\title{
The Ethics of e-Medicine
}

\author{
Göran Collste \\ Centre for Applied Ethics, Linköping University, Sweden, \\ gorco@cte.org.liu.se, \\ http://www.liu.se/cte/organisation/Goran_Collste.PDF
}

\begin{abstract}
E-medicine', i.e. the possibilities for patients to have access to medical information and medical consultation at Internet raises new ethical issues. In this paper e-medicine is discussed in terms of how it will affect the patient-doctor-relation, patient autonomy and the moral and professional responsibility of doctors.
\end{abstract}

Keywords: e-Medicine, ethics, Internet, patient-doctor relation, autonomy, responsibility.

\section{Introduction}

Since many years information and communication technology is used in health care. However, lately one can notice an accelerated interest for different kinds of ICTapplications. Internet is more and more used for providing medical information, medical consultation and drug prescriptions. Medical information can be accessed from an increasing number of medical information sites, patients can consult doctors on line, patients can get access to their medical record through Internet and drugs can be bought on line. Hence, health care is going through a transformation due to different applications of e-medicine. ICT can in different ways enhance the practice of health care. However, it is necessary to examine the application in the light of the ethical values of health care. As Pellegrino and Thomasma argue "Medicine is at all levels a moral enterprise where 'moral enterprise' means action involving values" [Pellegrino and Thomasma, 1981, p.112]. The new technologies must be instrumental in achieving the goals and values of health care and they must fit into health care practices.

When a patient uses Internet as a source of information about a disease, medicines or ways of treatment, it is an example of, what has been called, 'do-ityourself healthcare.' Consultation via the Internet is a way for those with sufficient economic resources to obtain a second opinion, yes, even a second doctor. There are

Please use the following format when citing this chapter:

Collste, G., 2006, in IFIP International Federation for Information Processing, Volume 223, Social Informatics: An Information Society for All? In Remembrance of Rob Kling, eds. Berleur, J., Numinen, M. I., Impagliazzo, J., (Boston: Springer), pp. 101-109 
many possible reasons for this demand: the patient may have lost confidence in her ordinary doctor, she has heard of some specialist in the particular disease she is suffering from, she finds herself in a desperate situation, etc. E-medicine is also a potential asset for health care in poor countries with limited health care resources.

The number of health sites on Internet is increasing. There are between 15,000 and 100,000 health-related sites in Great Britain and they have been visited by approximately 30 million people. [Parker and Gray, 2001]. A Swedish survey showed that of those who accessed Internet, about $20 \%$ had been looking for healthrelated information. [Garpenby and Husberg, 2000]

According to Swedish law, a patient has a right to access his or her medical record. However, in practice it is rare for patients to request to read their records spontaneously. [Ross and Lin, 2003, Sundberg, 2003, Bruzelius, 2004] A system for patient Internet accesses to his or her medical record is presently tried out in Swedish health care. Through a so-called 'patient portal' a patient can have direct access to his or her own medical record. This implies for example that the patient will have access to information about laboratory results before meeting a doctor. The technique used is similar to the technique for Internet banking. I.e. the patient will get a personal certificate with a pin code that secure that no one else will have access to the portal. The patient portal is so far tried out in a trial involving 100 voluntary patients, but will eventually be part of ordinary health care.

\section{The Relationship between Doctor and Patient}

The possibility to consult a doctor on line will have implications for the patientdoctor relationship. The clinical encounter has for many years been an issue for discussions in medical ethics. The relation between doctor and patient is embedded by values of commitment, trust, privacy, confidentiality and responsibility. One can distinguish between different kinds of relationship like, for example, caring and contractual. In connection to the new possibility of consultation on Internet one can ask what kind of relation will be established between patient and doctor on line. A new doctor-patient relationship is being established, i.e. between the Internet doctor and the patient, and this will also most likely affect the relation between the patient and the general practitioner.

The patient is in a vulnerable situation when his or her health is threatened and the clinical encounter is a means to recovery with the doctor as a mediator. [Pellegrino and Thomasma, 1981] With this bare description of the relationship between doctor and patient as a starting-point, I will outline the clinical interaction in different models, each focusing on specific aspects of the encounter. Which of the models resembles the relationship between the Internet doctor and the patient?

According to the engineering-model, the patient is an object for treatment, in relevant aspects similar to a broken car taken to the garage for repair. In the engineering-model of a clinical encounter, the doctor collects information in order to make a diagnosis and a decision on therapy. The information needed is, for instance, data on temperature, blood pressure etc. This model fits Tristran Engelhardt's description of "Medical care from passing strangers." [Engelhardt, 1986] 
Secondly, the clinical interaction may also, in accordance with Pellegrino and Thomasma, be modelled as a 'healing relationship' [Pellegrino and Thomasma, 1981]. Then, it is seen as an encounter between two persons, the doctor and the patient, which serves the purpose to achieve a mutual understanding, or, in the words of Martin Buber, an 'I/Thou relationship' [Buber, 1923]. This model pays attention to the fact that in many cases a disease is not only a threat to the health of the patient but also to her existential balance.

Thirdly, the relationship can also be modelled as one of trust or fidelity. [Ramsey, 1970]. Trust is based on two pillars, competence and sympathy. The patient can trust the doctor knowing that he/she is competent and knowing that he/she cares. The latter pillar highlights the moral aspects of the clinical encounter. The doctor cares about the patient and is obliged to do his/her best.

These models stress different aspects of the relationship between doctor and patient. They rather complete than exclude one another. The engineering model with its emphasis on scientific and technical relevance is essential for good treatment but the hermeneutic approach of the 'healing relationship' is needed to allow the doctor to make the right decision and to involve the patient in the treatment. In real life the doctor-patient relationship will more or less resemble any of these models.

How will medical care and the relation between doctor and patient be affected by Internet consultation? With which model does it correspond? There are now two parallel patient doctor relationships established, on the one hand between the patient and the GP and on the other hand between the patient and the Internet doctor. Firstly, one can assume that Internet consultation tends to resemble the engineering-model rather than a healing relationship. Consultation is made at a distance and based on raw data, at least as long as the technical possibilities for a web-based dialogue between doctor and patient are limited. However, this may change as a consequence of the development of interactive media communication. Still, one may doubt whether this kind of mediated form of communication, ever will be a valid substitute for a person-to-person dialogue. Similarly, one can argue that the trust model requires a personal encounter. If, however, trust is based on competence rather than care, it is possible that even Internet consultation could be of this kind. This, of course, presupposes that the Internet doctor is highly competent.

\section{3 e-Medicine and Patient Autonomy}

The principle of autonomy has become increasingly important in modern health care. The principle implies that anyone who is affected by a decision should be able to influence it and if a decision only concerns one individual, he/she should decide for him/herself. When applied to health care, the principle implies that the patient should be empowered to play a more active role in his/her own care. One-way to do this is that the patient has the opportunity to give informed consent to the decisions that concern her own treatment.

The principle of autonomy, or, the derived principle of informed consent, depends on some conditions. One is that there are alternatives available in the decision-making situation, another that the patient is competent and a third that the patient has access to relevant information. 
Only in situations where patients have a choice is it meaningful to speak of patient autonomy. Further, in order to be able to make an autonomous decision the patient must be competent. Competence implies an ability to understand and process information and to form a decision on the basis of the information. The information provided must be reliable and relevant.

What implications will access to medical consultation and information via Internet have for patient autonomy? One could argue that Internet would provide the patient with more information and, thus, enhance his/her autonomy. Access to an Internet doctor gives the patient a choice of a second opinion and access to medical information via Internet gives him/her access to new sources of information. However, in reality it is not as simple as that. When the patient contacts a doctor via Internet, how can she judge the quality of the doctor? Is it a competent doctor or just a quack?

A similar problem is connected to medical information via Internet. One can, at present, find a lot of websites for any disease. Presumably, these websites are normally trustworthy and contain reliable information. But this is not always the case. A study by American gastroenterologists found that one in ten of the healthrelated sites in the field offered unproven treatments. [Barkham, 2000] Pharmaceutical companies are responsible for some medical sites. Although they are presumably of a high standard, they are biased for commercial reasons. Thus, the patient will have problems distinguishing between reliable and less reliable sites. As a consequence, a patient looking for information about his/her disease and possible ways of treatment runs the risk of being misinformed. [Silberg, et al, 1997] Besides, all the problems connected to the transfer of information from health care provider to patient in ordinary health care will be present in e-medicine in more aggravated forms: Is the information provided in an understandable language? Is it adjusted to the ability of the patient to process the information? Does the patient really understand the prescription?

Beauchamp and Childress distinguish between three standards of disclosure of information: professional standard, the reasonable person standard and the subjective standard [Beauchamp and Childress, 2001]. Medical websites that disclose information for professionals provide new sources of information for doctors, but are of limited value for the ordinary patient. The sites for ordinary patients are usually written in a way that is understandable to a 'normal' reader. These sites can provide the patient with valuable information, helpful for anyone who wants to know more about a disease. Finally, the subjective standard takes the informational needs of the specific patient into consideration. This standard requires an interactive site, which provides the patient with opportunities to question the information presented. Thus, it seems that medical information via Internet can be a valuable source for patients wanting to learn more about their disease, provided that there are means to discern which sources are reliable. In this way, Internet will facilitate the fulfilment of the principle of patient autonomy in health care. 


\section{Will the Patient Portal Enhance Patient Autonomy?}

Patient electronic access to the medical record might also facilitate patient autonomy in health care. However, more information does not necessarily make patients better informed. For a patient to be able to handle information and use it in a constructive way, information provided must be comprehended and relevant. For sure, through access to the medical record the patient will have access to much information but one may ask - has he/she tools to handle it? If not, the information will not help in empowering the patient, but instead leave the patient confused and insecure. Some studies of non-electronic patient access to medical records confirm that patients commonly have difficulties in understanding parts of their records [Ross and Lin, 2003].

There is so far little empirical evidence of how electronic patient access to the medical records will influence autonomy. However, the evidence from other forms of patient access is predominantly positive. The majority of patients in several studies reported that reading their records educated them about their medical condition. Further, these studies do not confirm that the access generated anxiety or concern among the patients. Especially seems the access of obstetric patients to their records have had a positive effect on their sense of autonomy and self-efficacy [Ross and Lin 2003]. But, in contrast to the patient portal this access was mediated by a care-giver, who could explain the content and answer questions.

As a consequence of the introduction of patient portals, the notes in the medical record should rather be of a 'reasonable person standard', i.e. understandable for an 'average' patient, than of a 'professional practice standard', i.e. understandable for doctors only [Beauchamp and Childress, 2001]. However, this may also imply that the doctors write their notes with this restriction in mind and that some important information that requires to be written in a professional and technical language will be left out.

Then, is it a good idea to give the patient full access to his/her medical record? The record might contain information about the patient that is necessary for the doctor to record, but that can be harmful for the patient to read. For example, a doctor may have to record that a patient is untalented and therefore will not be expected to take his or her medicine as prescribed, or that battering may have caused some wounds on a child's body etc. The fact that the doctor has to record even unfavourable facts about patients in their best interest can be seen as a kind of weak paternalism. Thus, in cases like these what is in the best interests of the patient may come into conflict with the patient's right to have a full access to his or her own medical record.

Thus, there are two problems with giving the patient direct access to his/her medical record. It may lead to a less precise way of expressing relevant medical information and it may contain for the patient harmful information. A possible solution to these problems is that the information given to the patient is filtered. However, this would be very costly and also very difficult to implement. It would also lay a too heavy burden on the 'filterer' who is to decide what information that could pass through and according to what standard of language. 


\section{Consultation via Internet and the Principle of Responsibility}

How will medical consultation via Internet influence responsibility in health care? Before discussing this question I will outline a bare meaning of the concept of responsibility.

We say that some person $\mathrm{P}$ is responsible for the outcome $\mathrm{O}$ of an action $\mathrm{A}$, when $\mathrm{P}$ has intentionally done $\mathrm{A}$ in order to achieve $\mathrm{O}$. $\mathrm{P}$ who is responsible must be prepared to answer questions like: Why did you do A? Why did you want O? As a result of being responsible, if $O$ is a bad outcome, this is a reason to blame or punish $\mathrm{P}$ and, vice versa, if the outcome is good this is a reason to praise P. [Lucas, 1995]

However, in order to hold a person responsible, there are some conditions that have to be fulfilled. If the outcome, due to some factors that $P$ reasonably could not foresee, is different from what $\mathrm{P}$ intended, say $\mathrm{O} 1$ instead of $\mathrm{O}, \mathrm{P}$ is not responsible for O1. However, if $\mathrm{P}$ acts without bothering to get the necessary information, $\mathrm{P}$ is responsible for $\mathrm{O} 1$, if $\mathrm{O} 1$ could have been foreseen, had $\mathrm{P}$ bothered to inform $\mathrm{him} /$ herself sufficiently? Neither is it reasonable to say that $\mathrm{P}$ is responsible for $\mathrm{O}$, if $O$ is caused by an action that $P$ was forced to do.

The concept 'responsibility' is used both in moral and legal senses. The main differences are the criteria for evaluating the outcome and the sanctions following a blameworthy action. In law, a sovereign legislator formally decides the criteria for evaluation and sanctions. In morality, on the other hand, the social ethos provides the criteria for evaluation and sanctions.

There is also a third usage of responsibility, referring to professional practice. Professional responsibility is a kind of responsibility that combines traits of legal and of moral responsibility. The criteria for evaluation are basically moral, outlined in professional ethical codes. However, professional responsibility is similar to legal responsibility when the professional association has decided on some sanction, e.g. expulsion from the profession, for those who do not comply with the professional moral duties.

Let us now apply the concept of responsibility to medical practice. $P$, the doctor, recommends $\mathrm{A}$, for instance medication or surgery, in order to achieve O, i.e. the restoration of a patient's health. The doctor is responsible for medical treatment. This means that the doctor with the best intentions, and to the best of knowledge, makes a decision on treatment and prescription of medicine. If something goes wrong, the doctor will be questioned; 'Why did you recommend A?'

From the point of view of both moral and legal responsibility there are problems connected to therapy at distance via Internet. Firstly, the patient information provided might be insufficient. This is obviously the fact if the diagnosis is based solely on the patient's own story. If the Internet doctor also has access to the patient's records, there is a better basis for diagnosis and therapy. However, the doctor is still lacking the information otherwise received through a personal encounter face to face with a patient, as well as information obtained through a physical examination of the patient's body. Secondly, while lacking a personal encounter, the Internet doctor is less confident than a regular GP that the patient will follow the recommendations. The possibility of misunderstanding increases the risk that the patient will take the wrong drug or the wrong dosage. Taken together, these 
factors increase the risk of maltreatment. But it is a risk that the Internet doctor ought to be conscious about and, thus, he/she is morally responsible for the possible maltreatment.

When we ask about the Internet doctor's legal responsibility in the case of maltreatment we are entering precarious ground. Assuming that the Internet doctor is licensed as a doctor, principles for advisory services should be applied. However, one has to establish in what country the consultation is taking place. Is it in the country of the patient, of the doctor or somewhere between, in cyberspace perhaps? The answer is also decisive for the question: which law that should be applied? Thus, if, say, it can be decided that the consultant is an American citizen, a summons has to be issued against him/her in an American court. Further, if maltreatment leads to injury and the patient needs money for medical treatment, in what country, if any, will the insurance be paid? Possibly, even the operator of the server can be legally responsible in cases of medical service provided by non-professional consultants.

Is it possible to apply codes of professional responsibility in the case of maltreatment? If the Internet doctor is a member of the World Medical Association, he/she will be subject to the professional code of the association. This would imply that the professional criteria for evaluation and the sanctions for non-compliance would be applied, irrespective of the nationality of the doctor. This is an example of the advantage of an international professional association when dealing with a global technological system.

\section{What is the Difference?}

The possibility to consult doctors on Internet is of recent date. But, does the Internet doctor represent anything new? Have not people always consulted other doctors than their regular ones, for instance a friend or a radio doctor? And what is the difference between using Internet as a source of information and other media like medical handbooks and encyclopaedias?

There are similarities as well as differences between consulting a friend who is a doctor and an Internet doctor. One similarity is that the patient consults a second doctor and, as a consequence, this doctor becomes involved. A difference is that one important reason to seek help from a friend, i.e. the emotional component of trust, is lacking in the case of the Internet doctor. And this difference is important. You can count on the friend caring.

There are also similarities between a radio doctor and a doctor's question and answers column in a magazine on the one hand and the Internet doctor on the other. In all cases a sick or worried person gets advice concerning his/her particular worries. And this advice is given without the component of a personal emotional involvement. One difference, however, is that while the Internet doctor engages in a particular consultation, the radio or magazine doctor usually does not establish a personal doctor to patient interaction. Instead, he/she answers the particular questions in a general way so that anyone interested can take advantage of the recommendation. 
There are some obvious similarities between Internet as a source of medical information and medical handbooks. Both will provide the reader with information about diseases. An advantage with an Internet site is that it can continuously be updated. A possible difference is, as we have noticed, that it is more difficult to control the reliability of the Internet site, i.e. to distinguish a reliable source from a bluff.

\section{$7 \quad$ A Code of Conduct}

So far, there seems to be a lack of trust among the public in e-medicine. A Swedish survey showed that in a scale from 1 to 7 , where 1 represents 'no trust' and 7 represents 'great trust', the GP rates 6, medical handbooks 4 and the Internet 2,5. [Garpenberg and Husberg, 2000]

Organisations involved in e-medicine have, in order to counteract the lack of trust among the public, formulated a code of conduct. The code contains eight principles referring to trust, reliability and transparency. The first principle states:

"Any medical or health advice provided and hosted on this site will be given only by medically trained and qualified professionals unless a clear statement is made that a piece of advice offered is from a non-medically qualified individual or organisation."

The fourth principle states:

"Where appropriate, information contained on this site will be supported by clear references to source data..." Other principles refer to confidentiality, fairness and transparency concerning both authorship and sponsorship. [Health on the Net]

\section{Conclusion}

The continued evolution of e-medicine is a probable prospect for the future. This development has some obvious advantages. It will provide an increased access to doctor's consultation and it will make medical information more accessible. Emedicine will in different ways change the conditions for health care and the relationship between doctor and patient. As argued in this paper, there is a need to reconsider the implementation of principles of medical ethics in the light of this development. To meet this new situation, health care authorities should, in line with the maxim 'to guide rather than to guard', inform their patients about the reliable information sites. Through peer reviews, licensing or other ways of authorisation, it should be possible to identify those sites that are reliable. A digital signature can then mark these. Some kind of authorisation is also needed in order to distinguish professional Internet doctors and medical information sites from non-professional ones. The Code of Conduct established by the Health on the Net Foundation is a step in this direction.

The patient portal seems to be problematic from an ethical point of view. Even though it will provide patients with updated information about their health status, it may lead to impairment of the medical record and it may even be harmful for the 
patient. Hence, the patient portal is questionable both with reference to the principle of beneficence and the principle of non-malfeasance.

\section{References}

Barkham P. Is the net healthy for doctors? The Guardian Online 2000 Jun 8: 2.

Beauchamp, T. and Childress, J. Principles of Biomedical Ethics, (Oxford, Oxford University Press, 2001).

Bruzelius, M, Sammanfattning och slutsatser. Patientportalen. SKILL Studentkompetens AB, (unpublished) Linköping 2004.

Buber, M., Ich und Du, (Leipzig, Insel, 1923).

Engelhardt, T, The Foundations of Bioethics, (New York: Oxford University Press, 1986).

Garpenby, P \& Hisberg, M, 2000, Hälsoinformation idag och imorgon, CMT Rapport 2000:3, Linköpings universitet, Linköping (unpublished)

Health on the Net Foundation Code of Conduct, [http://www.hon.ch/HONcode/Conduct.html] 2006-03-09

Lucas, J R, Responsibility, (Oxford: Clarendon Press, 1995)

Parker, M \& Muir Gray, $\mathrm{J} A$, What is the role of clinical ethics support in the era of emedicine?, Journal of Medical Ethics, 2001; 27, suppl I:i, pp 33-35

Pellegrino, E.D., Thomasma, D.C. A Philosophical Basis of Medical Practice, (New York, Oxford University Press, 1981), p.112

Ramsey, P, The Patient as Person. Explorations in Medical Ethics, (New Haven: Yale University Press, 1970).

Ross, S.E. and Lin, C-T., The Effects of Promoting Patient Access to Medical Records: A Review. Journal of the American Medical Informatics Association, Vol 10, Nr 2, 2003.

Silberg, W M, Lundberg, G D, Musacchio, R A, , Assessing, Controlling, and Assuring the Quality of Medical Information on the Internet, Journal of American Medical Association, 277:1244-1245, 1997

Sundberg, A, Nulägesbeskrivning av attityder till patientportalen 2003, Landstinget i Östergötland, (unpublished), 2003. 